\title{
Stretchable and colorless freestanding microwire arrays for transparent solar cells with flexibility
}

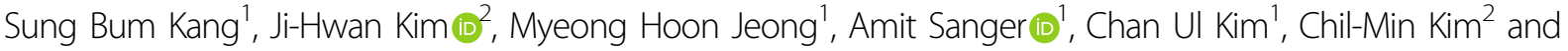 \\ Kyoung Jin Choi $^{1}$
}

\begin{abstract}
Transparent solar cells (TSCs) are emerging devices that combine the advantages of visible transparency and light-toelectricity conversion. Currently, existing TSCs are based predominantly on organics, dyes, and perovskites; however, the rigidity and color-tinted transparent nature of those devices strongly limit the utility of the resulting TSCs for realworld applications. Here, we demonstrate a flexible, color-neutral, and high-efficiency TSC based on a freestanding form of $n$-silicon microwires (SiMWs). Flat-tip SiMWs with controllable spacing are fabricated via deep-reactive ion etching and embedded in a freestanding transparent polymer matrix. The light transmittance can be tuned from $\sim 10$ to $55 \%$ by adjusting the spacing between the microwires. For TSCs, a heterojunction is formed with a p-type polymer in the top portion of the n-type flat-tip SiMWs. Ohmic contact with an indium-doped $\mathrm{ZnO}$ film occurs at the bottom, and the side surface has an $\mathrm{Al}_{2} \mathrm{O}_{3}$ passivation layer. Furthermore, slanted-tip SiMWs are developed by a novel solventassisted wet etching method to manipulate light absorption. Finite-difference time-domain simulation revealed that the reflected light from slanted-tip SiMWs helps light-matter interactions in adjacent microwires. The TSC based on the slanted-tip SiMWs demonstrates $8 \%$ efficiency at a visible transparency of 10\% with flexibility. This efficiency is the highest among Si-based TSCs and comparable with that of state-of-the-art neutral-color TSCs based on organic-inorganic hybrid perovskite and organics. Moreover, unlike others, the stretchable and transparent platform in this study is promising for future TSCS.
\end{abstract}

\section{Introduction}

Transparent solar cells (TSCs) are emerging as building blocks for building-integrated power generation ${ }^{1-4}$. In this attractive concept of photovoltaics, there is an unavoidable trade-off between the energy generation (i.e., the photovoltaic conversion efficiency (PCE)) and the light admission (visible transparency). Therefore, based on the criteria for transparent solar cells, there is an inevitable compromise of the efficiency to achieve transparency. The most common way to develop transparent solar cells is via band-gap engineering of active materials that can absorb sunlight selectively, resulting in tinted transparency ${ }^{5-9}$.

\footnotetext{
Correspondence: Kyoung Jin Choi (choi@unist.ac.kr)

${ }^{1}$ Department of Materials Science and Engineering, Ulsan National Institute of Science and Technology (UNIST), Ulsan 44919, Republic of Korea

2Department of Emerging Materials Science, Daegu Gyeongbuk Institute of

Science and Technology (DGIST), Daegu 42988, Republic of Korea
}

For example, when the active layers are designed to absorb short-wavelength light and transmit longwavelength light in the visible range $(\lambda>600 \mathrm{~nm})$, the transparent devices exhibit a yellow or reddish color $^{7-14}$. Previous attempts have been made to develop transparent solar cells by taking advantage of dyes as active materials. To obtain fully transparent dye-sensitized solar cells, a new design of dye sensitizers that ensures the absorption of visible light in the device may be effective ${ }^{15,16}$. Moreover, all components (including $\mathrm{TiO}_{2}$ and the electrodes) should also be transparent ${ }^{17-19}$. Through these strategies, some groups have demonstrated various tinted transparent solar cells with a low PCE of $\sim 3-7 \%$ with modest transparencies ${ }^{15-19}$. However, this tinted transparency is unsuitable for electronics, automobile windows, and office-building-integrated photovoltaic windows.

\section{(c) The Author(s) 2019}

(c) (i) Open Access This article is licensed under a Creative Commons Attribution 4.0 International License, which permits use, sharing, adaptation, distribution and reproduction cc) in any medium or format, as long as you give appropriate credit to the original author(s) and the source, provide a link to the Creative Commons license, and indicate if changes were made. The images or other third party material in this article are included in the article's Creative Commons license, unless indicated otherwise in a credit line to the material. If material is not included in the article's Creative Commons license and your intended use is not permitted by statutory regulation or exceeds the permitted use, you will need to obtain permission directly from the copyright holder. To view a copy of this license, visit http://creativecommons.org/licenses/by/4.0/. 
Recently, there has been flurry of interest in the field of photovoltaics, focused on organic-inorganic hybrid perovskite materials ${ }^{20-23}$. These $\mathrm{ABX}_{3}$-structured materials exhibit a suitable band gap and high-absorption coefficient, making them an intriguing class of photovoltaics ${ }^{24-28}$. Many groups have achieved halide perovskite-based transparent solar cells by controlling the thickness, transport layer, and composition of the perovskite. Introducing a thin layer with a band-gap engineered perovskite layer is a well-known technique for achieving transparent solar cells $^{29,30}$. Roldán-Carmona et al. $^{9}$ utilized common methylammonium lead iodide as an absorber, with variations in the thickness, and obtained a PCE of $6.4 \%$. Moreover, Jung et al. and Heo et al. ${ }^{8,31}$ employed modified hole or electron transport layers in their devices and demonstrated perovskite-based semi-transparent solar cells with a PCE of over $10 \%$. However, despite their high PCE, such devices have tinted transparency, again due to the compromise on color. Generally, because a perovskite is designed to absorb a part of the visible range of the solar spectrum as the active layer of transparent solar cells, the devices exhibit brown-yellow transparency. In addition, approaches for obtaining transparency are restricted because thinning the active layer or engineering the band gap is highly dependent on the materials ${ }^{5,7,12,14}$. Thus, the adjustable range of the transparency of the resulting devices is very limited. On the other hand, high-efficiency per transparency has also been achieved with organic-based transparent solar cells by taking advantage of designed semiconducting polymers. However, like the case with dyes and perovskites, it is difficult to obtain spectrally flat absorption across the entire visible spectrum with tailored polymers, which is a requirement for neutral-color transparent solar cells. Therefore, although Cui et al. ${ }^{32}$ obtained a PCE of $8.38 \%$ with a visible transparency of $25.7 \%$ using an ultralow-band-gap nonfullerene acceptor, the device was only transparent in the blue-green region of the visible spectrum. Liu et al. ${ }^{33}$ developed a new electron-acceptor material that shows strong Near-infrared (NIR) absorption between 600 and $940 \mathrm{~nm}$, and successfully applied it to transparent solar cells with blue-tinted transparency. Again, the tinted transparency of perovskite and organicbased TSCs is a major obstacle to real-world applications.

Herein, we demonstrate true-color transparent solar cells. A crystalline $\mathrm{n}$-Si microwire array with controllable spacing is fabricated via deep-reactive ion etching and embedded within a transparent polymer matrix. Subsequently, via a combination of dry and wet etching, a freestanding $\mathrm{Si}$ microwire array polymer composite film (SiMPF) is obtained by applying mechanical peel-off techniques. Furthermore, we apply a p-type conductive polymer on top of the $\mathrm{n}$-Si tips, enabling the formation of a junction between the polymer and $\mathrm{n}-\mathrm{Si}$, and fabricate a neutral-color transparent solar cell. The slanted-tip of the
n-SiMPF-based transparent solar cells leads to a power conversion efficiency of $8.07 \%$ at a visible transparency of $10 \%$ with flexibility. The developed devices have performances comparable with those of existing TSCs based predominantly on perovskites, dyes, and organics. Moreover, this robust, ultra-light and stretchable platform is promising for future transparent and stretchable solar cells to extend their applications.

\section{Results \\ Fabrication of freestanding Si microwire-poly (dimethylsiloxane) (PDMS) composite}

Figure 1a displays the overall process for the fabrication of the TSCs based on the freestanding film of an n-type SiMW array embedded in poly(dimethylsiloxane) (PDMS). As shown in Fig. 1b, a hexagonal array of microwires with a diameter of $2 \mu \mathrm{m}$ and a length of $30 \mu \mathrm{m}$ was fabricated by a photolithography process involving reactive ion etching (RIE) using a $\mathrm{Cr}$ dot array as the etching mask. Second, a 15-nm-thick $\mathrm{Al}_{2} \mathrm{O}_{3}$ layer was deposited on the SiMWs by atomic layer deposition (ALD) to passivate the Si surface. Compared to conventional silicon solar cells, the freestanding SiMPF-based TSCs in this study have a very high surface area; thus, proper surface passivation is essential. As shown in Fig. S1 (Supplementary Information), the TSC without $\mathrm{Al}_{2} \mathrm{O}_{3}$ passivation had a very low short-circuit current density $\left(J_{\text {sc }}\right)$ and open-circuit voltage $\left(V_{\text {oc }}\right)$ due to the very high leakage current caused by surface defects. Third, the SiMW array was embedded in PDMS via spin-coating. PDMS embedding was performed by a two-step spincoating process consisting of first spinning at $600 \mathrm{rpm}$ for $120 \mathrm{~s}$ and then spinning at $1500 \mathrm{rpm}$ for $10 \mathrm{~s}$. In the first step, PDMS conformally and densely filled the SiMW array; the excess PDMS residue on the top of the SiMWs was removed during the second spin-coating step. We found that the $\mathrm{Al}_{2} \mathrm{O}_{3}$-coated SiMW array was so hydrophobic that PDMS could not deeply penetrate the SiMW, and the adhesion between SiMW and PDMS was not very strong. Thus, PDMS was easily peeled off the SiMW array in the second spin-coating step (Fig. S2a, b, Supplementary Information). The surface of the $\mathrm{Al}_{2} \mathrm{O}_{3}$-coated SiMWs was subjected to $\mathrm{O}_{2}$-plasma treatment, which enhanced the adhesion between the $\mathrm{Al}_{2} \mathrm{O}_{3}$ surface and PDMS due to covalent bonding of $\mathrm{O}-\mathrm{Si}^{34-36}$. Figure 1c presents an scanning electron microscope (SEM) image of the SiMW array embedded in PDMS, and it can be seen that PDMS deeply penetrated the SiMW array after the oxygen plasma treatment. Fourth, the residual PDMS layer was removed by dry etching using a gaseous mixture of $\mathrm{O}_{2}$ and $\mathrm{SF}_{6}$. PDMS could be selectively etched because the SiMWs were protected by the $\mathrm{Al}_{2} \mathrm{O}_{3}$ film, which was very slowly etched by $\mathrm{SF}_{6}$ gas. Fifth, the $\mathrm{SiMW}$ array embedded in PDMS was peeled off the $\mathrm{Si}$ wafer, 
a

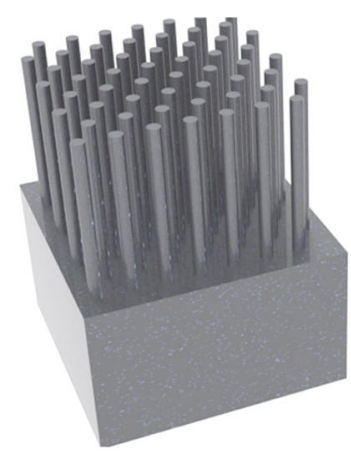

Fabrication of SiMWs via dry etching

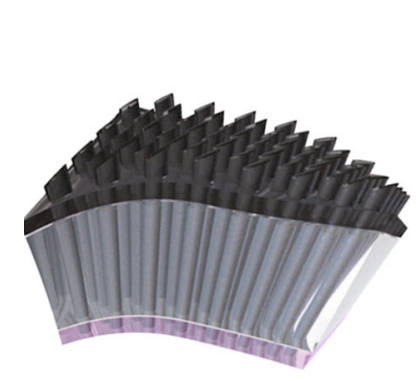

Deposition of IZO and Coating of PEDOT:PSS

b

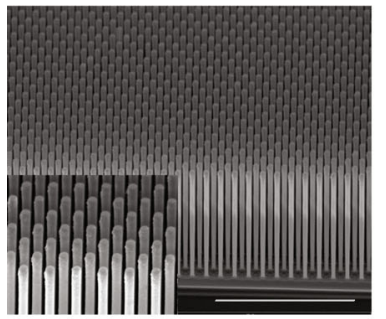

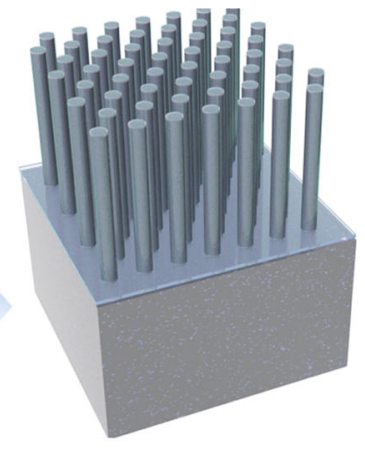

Deposition of $\mathrm{Al}_{2} \mathrm{O}_{3}$

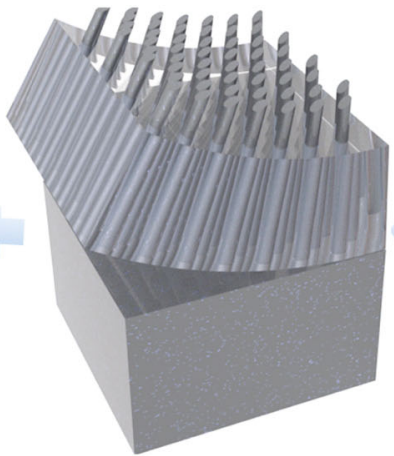

Peel off of SiMPF and Removal of residual PDMS

C

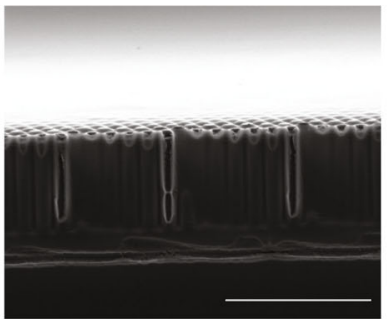

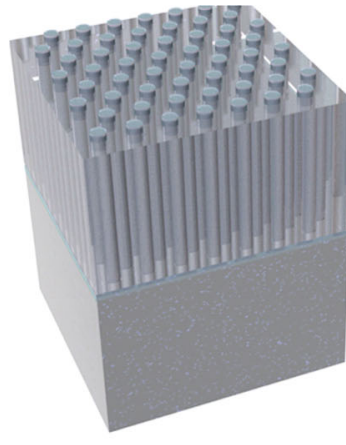

Coating of PDMS

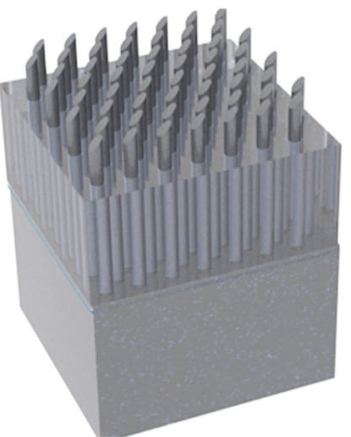

Dry etching of PDMS and wet etching of $\mathrm{Al}_{2} \mathrm{O}_{3} \& \mathrm{Si}$

d

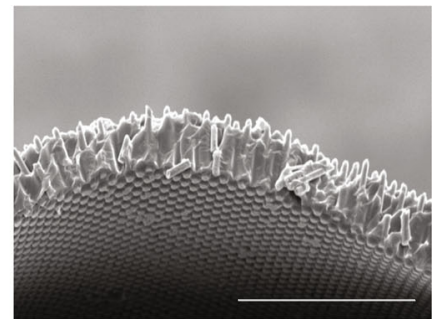

Fig. 1 Experimental procedure of SiMPF composite. a Schematic of fabrication process. SEM images of $\mathbf{b}$ Si microwire arrays in a bird's-eye view (scale bar: $50 \mu \mathrm{m})$, c Si microwire array filled with PDMS after surface treatment (scale bar: $50 \mu \mathrm{m}$ ), and $\mathbf{d}$ freestanding SiMPF after peeling off from the Si parent (scale bar: $100 \mu \mathrm{m})$.

producing a flexible SiMPF as shown in Fig. 1d. The pitch and hexagonal arrangement of the SiMW array were maintained even after peeling off from the parent substrate, as manifested by the hexagonal array of diffraction spots when SiMPF was perpendicularly illuminated with a 532-nm diode laser (Fig. S3 and Movie S1, Supplementary Information). Finally, the TSC process was completed by forming a hetero $\mathrm{p}-\mathrm{n}$ junction with PEDOT:PSS at the exposed tips and the indium-doped zinc oxide (IZO) ohmic contact at the bottom of the SiMPF.

After the pitch, defined as the center-to-center distance of the microwire, was varied from 4 to $7 \mu \mathrm{m}$ at $1 \mu \mathrm{m}$ intervals (Fig. S4, Supplementary Information). Figure
S5a, b show the current density (J)-voltage (V) characteristics and external quantum efficiencies (EQEs) of the TSCs based on flat-tip SiMW arrays. A summary of the device characteristics is presented in Table 1. Moreover, the box plot of $J_{\mathrm{sc}}, V_{\mathrm{oc}}$, and the efficiency of eight solar cells fabricated at pitch has a fairly narrow distribution, indicating that this fabrication process is fairly reproducible, as shown in Fig. S6. Compared to bulk solar cells, nanowire or microwire solar cells typically have a very high surface area and, consequently, a high concentration of surface defects that act as leakage current paths ${ }^{37,38}$. However, the deposited $\mathrm{Al}_{2} \mathrm{O}_{3}$ layer provides a high density of negative charges with a very low-density of 
Table 1 Average photovoltaic performance from 8 samples of flat-tip SiMPF-based transparent solar cells with controlled spacing between microwires.

\begin{tabular}{llcll}
\hline Pitch $(\boldsymbol{\mu m})$ & $\boldsymbol{V}_{\text {oc }}(\mathbf{V})$ & $J_{\mathbf{s c}}\left(\mathbf{m A} / \mathbf{c m}^{2}\right)$ & FF & Eff. (\%) \\
\hline 4 & $535(542)$ & $17.75(18.3)$ & $67.5(68.1)$ & $6.41(6.75)$ \\
5 & $519(522)$ & $11.34(12.24)$ & $65.0(65.7)$ & $3.83(4.19)$ \\
6 & $485(493)$ & $9.18(9.54)$ & $59.8(60.4)$ & $2.66(2.84)$ \\
7 & $452(456)$ & $7.12(7.74)$ & $55.8(56.2)$ & $1.8(1.98)$ \\
\hline Values in the brackets are & the photovoltaic performance & from the
\end{tabular}
champion device

Table 2 Optical properties (reflectance, transmittance) of flat-tip SiMPF.

\begin{tabular}{lllll}
\hline Flat averaged reflectance & & & & \\
\hline Pitch $(\mu \mathrm{m})$ & 4 & 5 & 6 & 7 \\
Visible + NIR (400-1100 nm) & 11.84 & 13.90 & 12.02 & 10.48 \\
Visible (400-800 nm) & 10.10 & 11.60 & 10.57 & 9.44 \\
Near-IR (800-1100 nm) & 14.22 & 17.05 & 14.01 & 11.90 \\
Averaged transmittance & & & & \\
Pitch ( $\mu$ m) & 4 & 5 & 6 & 7 \\
Visible + NIR (400-1100 nm) & 10.05 & 26.85 & 39.95 & 50.81 \\
Visible (400-800 nm) & 10.23 & 24.95 & 38.53 & 50.28 \\
Near-IR (800-1100 nm) & 9.80 & 29.46 & 41.89 & 51.52 \\
Averaged absorbance & & & & \\
Pitch ( $\mu \mathrm{m})$ & 4 & 5 & 6 & 7 \\
Visible + NIR (400-1100 nm) & 78.11 & 59.24 & 48.03 & 38.71 \\
Visible (400-800 nm) & 79.66 & 63.45 & 50.90 & 40.28 \\
Near-IR (800-1100 nm) & 75.98 & 53.49 & 44.10 & 36.58 \\
\hline
\end{tabular}

interface defects ${ }^{39-41}$. Thus, the surface defects and dangling bonds can be effectively passivated. In addition, the presence of negative charges at the interface with silicon avoids parasitic shunting ${ }^{42}$.

Therefore, as shown in Fig. S5a and Table 1, the photovoltaic parameters of the $4-\mu \mathrm{m}$ pitch cell were $0.542 \mathrm{~V}$ and $68.1 \%$, which are comparable to those of the bulk counterparts. This means that the heterojunction between the n-type $\mathrm{Si}$ and p-type PEDOT:PSS works as an excellent rectifying junction, and the $\mathrm{Al}_{2} \mathrm{O}_{3}$ layer also efficiently passivates the silicon surface defects. As the pitch of the SiMW increased, the $J_{\mathrm{sc}}$ of the TSCs decreased, which can be explained by the decrease in the optical absorption. As the pitch increased from 4 to $7 \mu \mathrm{m}$, the average optical absorption of the TSCs at wavelengths of $400-1100 \mathrm{~nm}$ was reduced from 78.11 to $38.71 \%$ (Table 2 ), which is in good agreement with the reduction in the
$J_{\text {sc }}$. Similar to the change in the $J_{\mathrm{sc}}$, the $V_{\mathrm{oc}}$ is also inversely proportional to the optical transmittance because the $V_{\mathrm{oc}}$ of a conventional solar cell is related to the photocurrent $\left(I_{\mathrm{L}}\right)$ and the saturation current $\left(I_{0}\right)$ as follows: $V_{\mathrm{oc}} \sim \ln \left(I_{\mathrm{L}} /\right.$ $\left.I_{0}+1\right)^{43,44}$. Owing to the dependency of $V_{\mathrm{oc}}$ and $J_{\mathrm{sc}}$ on the optical transparency, the efficiency of the TSCs also has a trade-off relationship with the optical transparency, which is inevitable in TSCs.

\section{Enhancing the light absorption of SiMPF via engineering light absorption}

Nanowire arrays are known to have excellent light antireflection properties due to their graded refractive index effects and light-trapping ability ${ }^{45-48}$. Thus, nanowire arrays can have lower reflection than microwire arrays. However, nanowire arrays are manufactured by top-down methods ${ }^{49-51}$, including electron beam lithography and subsequent etching, or bottom-up methods ${ }^{52-54}$, including the vapor-liquid-solid method. Both methods have very limited scalability of the overall area. Moreover, these arrays have a very high surface-to-volume ratio, which increases the possibility of surface recombination and degrades performance ${ }^{38,55,56}$. In contrast, wafer-scale microwire arrays are manufactured by photolithography and etching processes that are now widely used in the semiconductor industry. In addition, microwire arrays are advantageous for forming effective junctions, allowing for easy carrier collection ${ }^{37,57}$. Therefore, SiMWs with reduced reflectance can be a promising candidate for TSCs. Assuming that the reflectance of the SiMWs is simply proportional to the area of the top flat surface of the microwire array, the average calculated reflectance obtained with the SiMWs having a pitch of $4 \mu \mathrm{m}$ was as high as $9.54 \%$ (Fig. S7a, Supplementary Information). Thus, to reduce the high reflectance from the flat-tip SiMWs, anti-reflective (AR) coatings or surface texturing techniques, which are typically adopted in bulk silicon solar cells, can be applied. First, we fabricated a TSC with a 70-nmthick SiN AR coating on the SiMW tips deposited by plasma-enhanced chemical vapor deposition (PECVD). Figure S7b shows the $J-V$ characteristics of the TSC based on the 4- $\mu$ m-pitched SiMW arrays with SiNx. With the use of the antireflection film, the $J_{\text {sc }}$ increased from 17.07 to $18.94 \mathrm{~mA} / \mathrm{cm}^{2}$, but the $V_{\text {oc }}$ and FF decreased simultaneously, resulting in no significant improvement in the efficiency compared to that of the TSC without the SiN layer. The reduction in the $V_{\text {oc }}$ can be attributed to the fact that the $\mathrm{n}$-Si and p-PEDOT heterojunctions are formed only on the side surface, not on the top surface of the SiMWs, thereby failing to efficiently separate the electronhole pairs. Thus, attempts were made to reduce the light reflection by changing the shape of the flat-tip SiMWs (Fig. 2a). For this purpose, a 70-nm-thick $\mathrm{SiO}_{2}$ thin film was formed on the tips of the SiMWs as an etching mask, and 
a

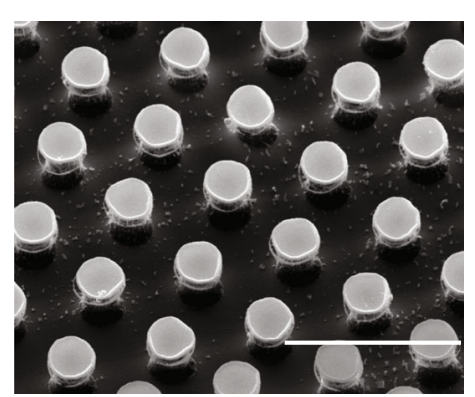

d
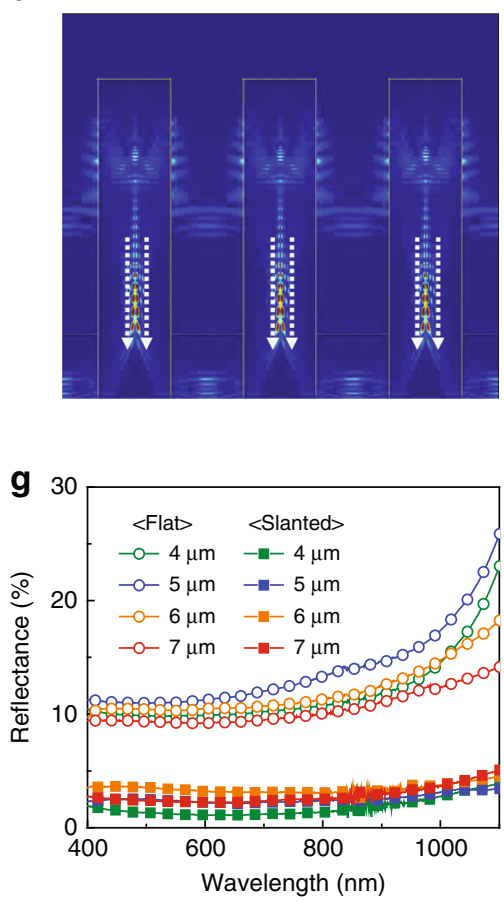

b

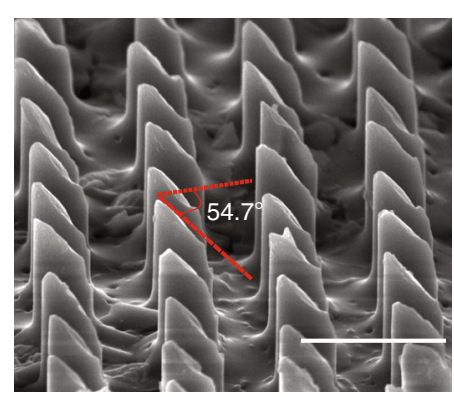

$\mathbf{e}$

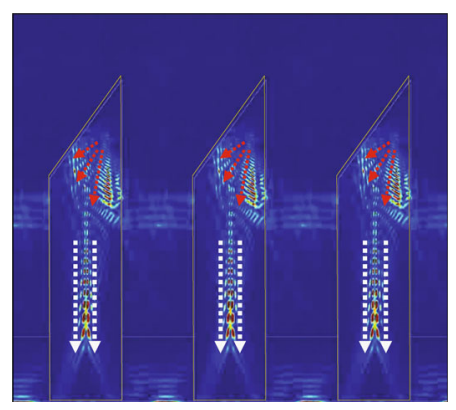

h 60

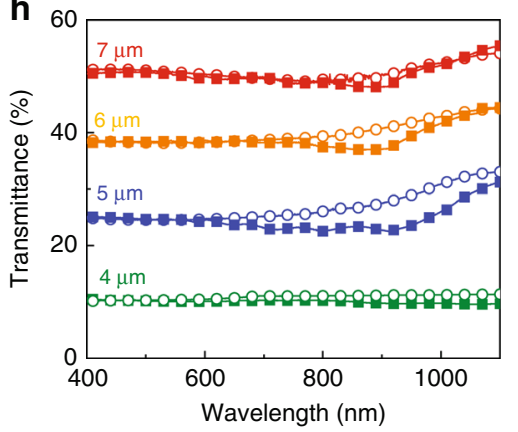

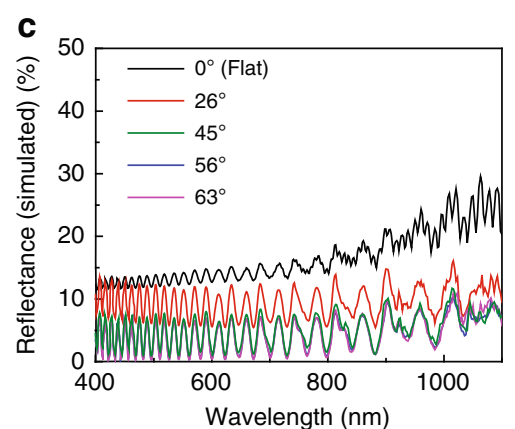

f

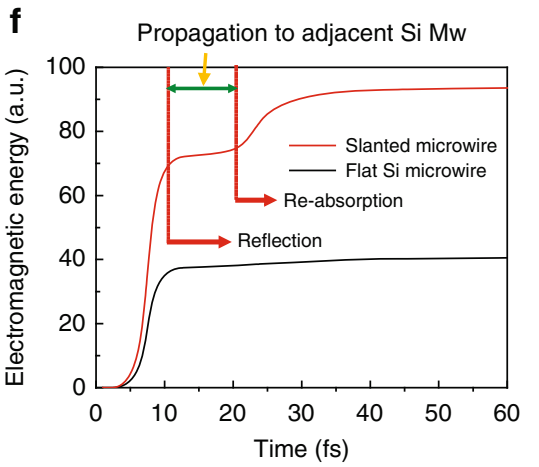

i

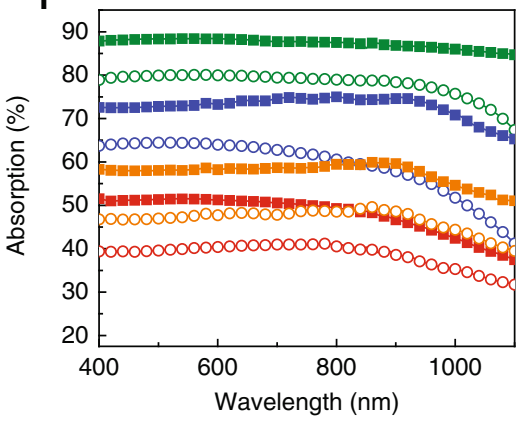

Fig. 2 Enhancing the light absorption of SiMPF by etching. a SEM image of flat-tip SiMPF without etching (scale bar: $10 \mu \mathrm{m}$ ). b Slanted-tip SiMPF with etching by HNAD solution having a $\mathrm{HF}: \mathrm{HNO}_{3}: \mathrm{CH}_{3} \mathrm{COOH}$ : DMF volume ratio of 3:6:0.3:0.7 (scale bar: $5 \mu \mathrm{m}$ ). c Simulated reflectance of SiMPF with difference angle of etched surface. The electric field intensity in the $\mathbf{d}$ flat and $\mathbf{e}$ slanted-tip SiMPF. $\mathbf{f}$ The total amount of electromagnetic energy in a single flat-tip SiMPF (black solid line) and slanted-tip SiMPF (red solid line). $\mathbf{g}$ Transmittance spectra of the slatned SiMPF of different center-to-center distance between microwires. $\mathbf{h}$ Reflectance spectra of the flat-tip (circle dot) and slanted-tip SiMPF (square dot) as a function of wavelength. $\mathbf{i}$ The total amount of absorption in slanted-tip SiMPF: $4 \mu \mathrm{m}$ (green line), $5 \mu \mathrm{m}$ (blue line), $6 \mu \mathrm{m}$ (yellow line), and $7 \mu \mathrm{m}$ (red line).

the SiMWs were chemically etched using a hydrofluoric acid-nitric acid-acetic acid (HNA) mixture solution ${ }^{58-61}$. Silicon etching using the HNA solution proceeds in three steps as follows:

$$
\begin{aligned}
& \mathrm{Si}+2 \mathrm{H}^{+} \rightarrow 2 \mathrm{Si}^{2+}+\mathrm{H}_{2} \\
& \mathrm{Si}^{2+}+2 \mathrm{OH}^{-} \rightarrow \mathrm{Si}(\mathrm{OH})_{2} \rightarrow \mathrm{SiO}_{2+} \mathrm{H}_{2} \\
& \mathrm{SiO}_{2}+6 \mathrm{HF} \rightarrow \mathrm{H}_{2} \mathrm{SiF}_{6}
\end{aligned}
$$

The overall reaction is initiated by breaking the covalent bonds between the silicon atoms by $\mathrm{H}^{+}$ions supplied from $\mathrm{HNO}_{3}$, producing $\mathrm{SiO}_{2}$ by recombination of $\mathrm{Si}^{2+}$ ions with hydroxide ions. Thereafter, HF dissolves the silicon dioxide to produce an aqueous salt. On the other hand, $\mathrm{CH}_{3} \mathrm{COOH}$ acts as a diluent to prevent excessive dissociation of $\mathrm{HNO}_{3}$ and to adjust the etching rate and the roughness of the etched surface. SiMPF was vigorously etched and even partially removed from the PDMS matrix in the HNA solution with a composition of a 3:7:0, whereas the etching rate was considerably attenuated in the HNA etching solution with a 3:6:1 composition ratio (Fig. S8a, b, Supplementary Information). However, the SiMWs were still extensively etched by the solution, leaving only the $\mathrm{Al}_{2} \mathrm{O}_{3}$ layer behind. To reduce the etching rate and change the behavior of HF- 
Table 3 Optical properties (reflectance, transmittance) of slanted-tip SiMPF.

\begin{tabular}{lllll}
\hline Slanted averaged reflectance & & & & \\
\hline Pitch $(\mu \mathrm{m})$ & 4 & 5 & 6 & 7 \\
Visible + NIR (400-1100 nm) & 1.80 & 2.55 & 3.44 & 2.85 \\
Visible (400-800 nm) & 1.30 & 2.33 & 3.31 & 2.40 \\
Near-IR (800-1100 nm) & 2.49 & 2.85 & 3.62 & 3.46 \\
Averaged transmittance & & & & \\
Pitch $(\mu \mathrm{m})$ & 4 & 5 & 6 & 7 \\
Visible + NIR (400-1100 nm) & 10.87 & 24.65 & 39.03 & 50.33 \\
Visible (400-800 nm) & 10.61 & 24.08 & 38.28 & 49.89 \\
Near-IR (800-1100 nm) & 11.22 & 25.44 & 40.06 & 50.94 \\
Averaged absorbance & & & & \\
Pitch ( $\mu \mathrm{m})$ & 4 & 5 & 6 & 7 \\
Visible + NIR (400-1100 nm) & 87.33 & 72.80 & 57.52 & 46.82 \\
Visible (400-800 nm) & 88.09 & 73.59 & 58.41 & 47.71 \\
Near-IR (800-1100 nm) & 86.29 & 71.72 & 56.32 & 45.60 \\
\hline
\end{tabular}

based etching, various additives, including organics, were introduced into the HF solution ${ }^{61,62}$. Surprisingly, the etching rate was significantly reduced with the etching solution in which Dimethylformamide (DMF) was added instead of acetic acid, and this dramatically changed the shape of the SiMW tip (Fig. S8c). The interaction between the HF and DMF molecules leads to the formation of heteroassociates. These heteroassociates have a pyramidal molecular structure consisting of three $\mathrm{H}-\mathrm{F}$ bonds $(\mathrm{H}$ on DMF and $F$ on HF), which leads to redistribution of the electron density of $\mathrm{HF}^{63}$, thereby greatly reducing the etching rate of $\mathrm{SiO}_{2}$. As a result, the etching rate of the native oxide (as an etching intermediate), as well as that of the $\mathrm{SiO}_{2}$ etching mask layer on the top surface of the SiMWs, is significantly reduced, which modifies the shape of the SiMW tips while maintaining the overall morphology of the SiMWs. Furthermore, we conducted a series of etching experiments while varying the volume ratio of the $\mathrm{HF}-\mathrm{HNO}_{3}-\mathrm{CH}_{3} \mathrm{COOH}-\mathrm{DMF}$ (HNAD) etching solution and found that the HNAD solution with a volume ratio of 30:60:3:7 generated SiMWs with well-defined, uniform, slanted tips, as shown in Fig. 2b. The measured angle of the slanted SiMW tips was $\sim 54.7^{\circ}$. Simulation of the angle-dependent reflectance of the slanted-tip also shows that the reflectance decreased up to an angle of $45^{\circ}$, thereafter reaching saturation (Fig. 2c). Finite-difference time-domain (FDTD) simulations were conducted to study the reflection and absorption of light from the flat and slanted SiMW tips. Approximately $40 \%$ of visible and infrared light was reflected by SiMPF with the flat-tip; thus, the strength of the electric field inside the SiMWs was low (Fig. 2d). On the other hand, light incident to the slanted-tip of the SiMWs was reflected towards the inside of SiMPF and eventually re-absorbed by adjacent SiMWs, thereby increasing the intensity of the electric field inside the SiMWs. Moreover, the low reflectance of the slantedtip SiMPFs is mainly due to re-absorption of reflected light from the slanted-tip by adjacent microwires (Fig. 2e). The time difference between the two absorption events provides evidence that reflected light from the slanted-tip MWs is re-absorbed by adjacent SiMWs. After $10.5 \mathrm{fs}$, the electromagnetic energy inside the SiMWs increases again, suggesting that the reflected light propagates to adjacent SiMWs for $10.5 \mathrm{fs}$. When multiplying by the group velocity of their pulse ${ }^{64}$, it corresponds to $3.17 \mu \mathrm{m}$. This is in good agreement with the distance between the center of the SiMWs to the edge side of the adjacent Si MW, indicating that reflected light from the slanted-tip is reabsorbed by adjacent wires (Fig. 2f). Therefore, the absorbed electromagnetic energy of the slanted-tip microwires consists of electric fields from the nonreflected light (white arrow, Fig. 2d) and the scattered electric field from re-absorbed light due to refracted light (red arrow, Fig. 2e). Figure $2 \mathrm{~g}-\mathrm{i}$ show the reflection, transmission, and absorption spectra of SiMPF with flat and slanted tips as a function of the pitch obtained by UV-Vis spectroscopy measurements. As predicted, the average reflectance decreased dramatically from 10.48 to $13.90 \%$ for the flat-tip SiMPFs to 1.81 to $3.45 \%$ for the slanted-tip counterparts (Table 3). Notably, the flat-tip SiMPF with a pitch of $4 \mu \mathrm{m}$ or the highest density of microwires had the lowest reflectance. This can be explained by light-trapping effects from scattering and diffraction due to the narrow spacing $(\sim 2 \mu \mathrm{m})$ between the SiMWs ${ }^{65,66}$.

The transmittance spectra of the flat and slanted-tip SiMPFs are predominantly determined by the pitch and were similar, except that the transmittance of the slanted samples was slightly lower than that of the planar sample in the long-wavelength regime. The light absorption coefficient of silicon is small due to the indirect band-gap structure and tends to decrease exponentially with increasing wavelength ${ }^{67,68}$. Therefore, the $30-\mu \mathrm{m}$-thick silicon layer used in this study may not completely absorb 1 -sun illumination ${ }^{69}$. Time-resolved light-tracing simulation was performed at two wavelengths (short: $550 \mathrm{~nm}$ ) and (long: $900 \mathrm{~nm}$ ) to elucidate the origin of this difference in the transmittance of the flat and slanted samples. With short-wavelength incident light, the light intensity was rapidly attenuated as the depth of the microwire increased for both the flat and slanted samples, indicating that the short-wavelength light is fully absorbed by 30$\mu \mathrm{m}$-thick Si (Fig. S9a, b). On the other hand, with longwavelength incident light on the flat-tip SiMWs, the light absorption was so weak that a significant portion of the 

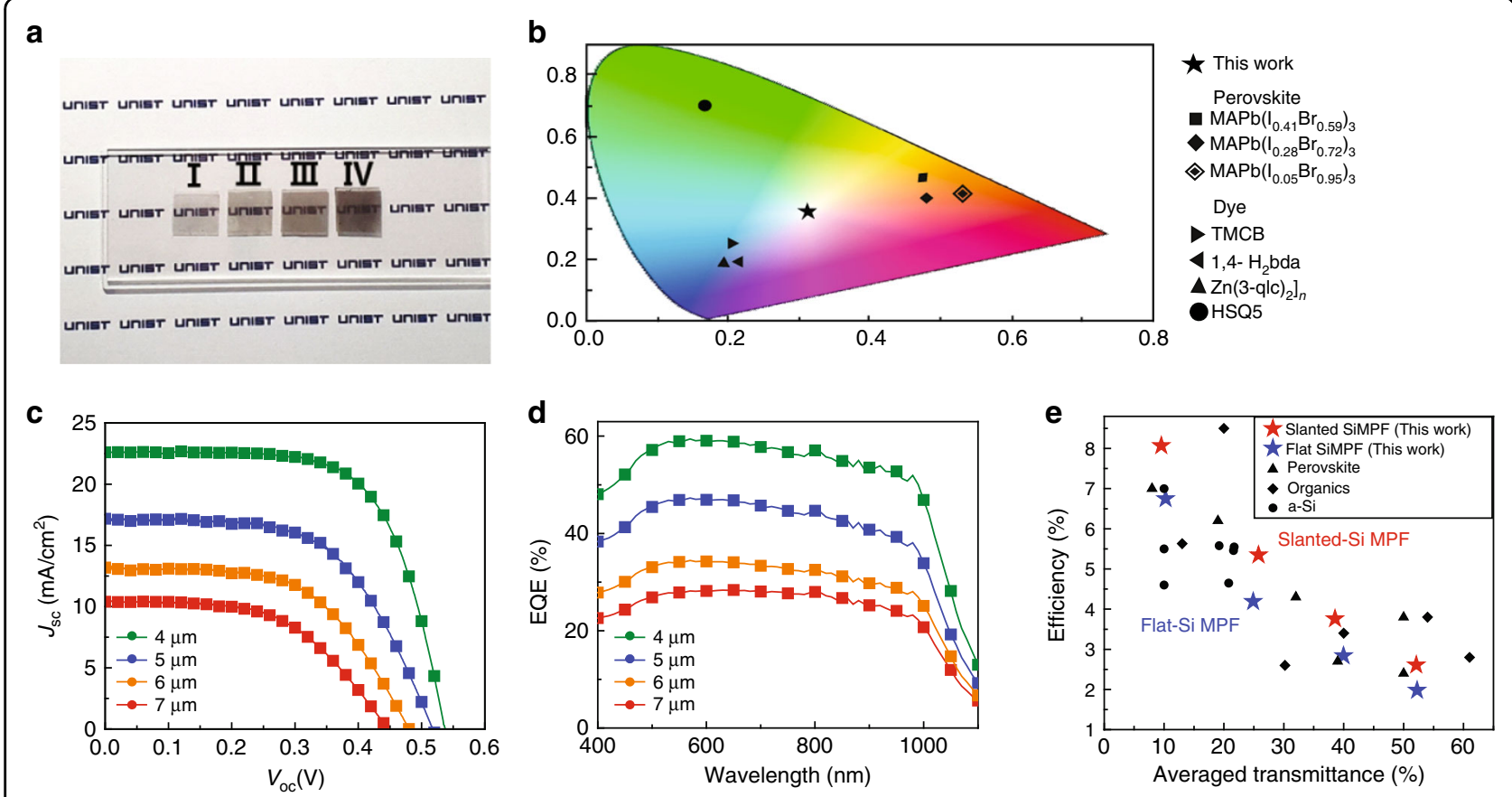

Fig. 3 Performance of transparent solar cells based on the slanted-tip SiMPF. a Optical images of freestanding slanted-tip SiMPF. b The representation of the color coordinates of slanted-tip SiMPF (black star, this work), halide perovskites (black diamond, black square, and white diamond containing small black diamond), dyes (black right pointing triangle, black left pointing triangle, black up pointing triangle, and black circle) with AM1.5 G illumination on the CIE chromaticity diagram. c J-V characteristics and d EQE of slanted-tip SiMPF-based transparent solar cells: $4 \mu$ m (green line), $5 \mu \mathrm{m}$ (blue line), $6 \mu \mathrm{m}$ (yellow line), and $7 \mu \mathrm{m}$ (red line). e The comparisons with previous reported neutral-color transparent solar cells based on halide perovskite, dye, a- Si, and organics.

light was transmitted through the bottom of the SiMW (Fig. S10a). However, when long-wavelength light was incident on the slanted-tip at an incidence angle of $50^{\circ}$, the light underwent refraction at the air-silicon interface, and thus the light inside the microwire followed a zigzag path (Fig. S10b), thereby increasing the effective light path or decreasing the transmittance (Fig. 2h). As a result, the absorption, calculated from the reflection and transmittance data, was significantly improved in the slanted-tip SiMPF (Fig. 2i). For example, the absorption in the SiMWs with a pitch of $5 \mu \mathrm{m}$ increased (by 13.56\%) from $59.24 \%$ for the flat-tip sample to $72.80 \%$ for the slanted-tip counterpart. The average reflectance, transmittance, and absorption of the flat and slanted-tip SiMPFs are summarized in Tables 2 and 3.

For the application of TSCs, the haze value is important because it can reduce clarity when viewing something through the TSC. The haze value represents light scattering and was calculated using the following equation:

$$
\operatorname{Haze}(\%)=\frac{T_{\text {diffuse }}}{T_{\text {total }}} \times 100 \%
$$

where $T_{\text {total }}$ is the total transmittance and $T_{\text {diffuse }}$ is the diffuse transmittance (detailed measurement methods in Fig. $\quad$ S11 and Supplementary Information $)^{70,71}$. As expected, the narrower the pitch between the microwires is, the higher the substantial degree of scattering. Thus, the sample with a lower pitch showed a higher haze ratio. For a narrow pitch of $4 \mu \mathrm{m}$, the haze values are relatively high, i.e., $>15 \%$. On the other hand, samples with a $7-\mu \mathrm{m}$ pitch show very low haze values of $\sim 2.5 \%$, which are even comparable with those of indium tin oxide or ultra-thin silver nanowires, which have $1-3 \%$ haze values (Fig. $\mathrm{S} 12 \mathrm{a})^{72-74}$. Interestingly, the lower the pitch is, the larger the haze ratio difference between flat and slanted sample. The slanted-tip of the microwire allows the light inside the microwire to follow a zigzag path (Path "A" in Fig. $\mathrm{S} 12 \mathrm{~b})$ or reflect towards an adjacent microwire (Path "B" in Fig. S12b). Light following path "A" is almost absorbed. On the other hand, the light in path "B" may cause secondary scattering to adjacent $\mathrm{Si}$, resulting in the increased haze for the samples with particularly low pitch.

Figure 3a presents an optical photograph showing the neutral-color perception of the SiMPFs with a controlled pitch, unlike the perovskite filter. Samples with pitches of $7 \mu \mathrm{m}$ (I), $6 \mu \mathrm{m}$ (II), $5 \mu \mathrm{m}$ (III), and $4 \mu \mathrm{m}$ (IV) are displayed on a university logo background. The transparency changed according to the pitch, but the color was perceived without distortion. For precise evaluation of the color perception, the SiMPF was illuminated with 
Table 4 The color coordinates of dye, perovskite, and SiMPF represented in the CIE 1931 chromaticity diagram.

\begin{tabular}{|c|c|c|c|c|}
\hline \multirow[t]{2}{*}{ Materials } & \multirow[t]{2}{*}{ Color } & \multicolumn{2}{|c|}{ CIE 1931} & \multirow[t]{2}{*}{ Ref. } \\
\hline & & $x$ & $y$ & \\
\hline \multicolumn{5}{|l|}{ Dye } \\
\hline HSQ5 & Green & 0.68 & 0.19 & [16] \\
\hline TMCB & Blue & 0.21 & 0.20 & {$[76]$} \\
\hline $1,4-\mathrm{H}_{2} \mathrm{bda}$ & Blue & 0.19 & 0.21 & {$[75]$} \\
\hline $\left.\mathrm{Zn}(3-q \mid c)_{2}\right]_{\mathrm{n}}$ & Blue & 0.19 & 0.17 & {$[75]$} \\
\hline \multicolumn{5}{|l|}{ Perovskites } \\
\hline $\operatorname{MAPb}\left(\mathrm{I}_{0.05} \mathrm{Br}_{0.95}\right)_{3}$ & Brown & 0.53 & 0.42 & This study \\
\hline $\operatorname{MAPb}\left(\mathrm{I}_{0.28} \mathrm{Br}_{0.72}\right)_{3}$ & Brown & 0.47 & 0.40 & This study \\
\hline $\operatorname{MAPb}\left(\mathrm{I}_{0.41} \mathrm{Br}_{0.59}\right)_{3}$ & Yellow & 0.46 & 0.47 & This study \\
\hline SiMPF & Gray (neutral) & 0.34 & 0.34 & This study \\
\hline
\end{tabular}

Table 5 Average photovoltaic performance from 8 samples of slanted-tip SiMPF-based transparent solar cells with controlled spacing between microwires.

\begin{tabular}{lllll}
\hline Pitch $(\mu \mathrm{m})$ & $\boldsymbol{V}_{\text {oc }}(\mathrm{V})$ & $J_{\text {sc }}\left(\mathrm{mA} / \mathbf{c m}^{2}\right)$ & FF & Eff. (\%) \\
\hline 4 & $533(537)$ & $21.84(22.54)$ & $66.1(66.7)$ & $7.70(8.07)$ \\
5 & $511(516)$ & $16.77(17.08)$ & $60.1(60.8)$ & $5.15(5.35)$ \\
6 & $476(479)$ & $12.81(13.47)$ & $57.3(58.2)$ & $3.49(3.75)$ \\
7 & $445(450)$ & $9.98(10.43)$ & $54.6(55.7)$ & $2.42(2.61)$ \\
\hline
\end{tabular}

Values in the brackets are the photovoltaic performance from the champion device

simulated AM1.5 light, and the color coordinates of the transmitted light were represented on the CIE 1931 chromaticity diagram, as shown in Fig. $3 \mathrm{~b}$ and Table 4. For comparison, the color coordinates of various dyes commonly used in dye-sensitized solar cells (DSSCs) and $\mathrm{MAPbI}_{x} \mathrm{Br}_{3-x}$ perovskite films are also displayed. The perovskite thin films were fabricated in this study, and the data for the dyes with the DSSCs were referenced from other publications ${ }^{16,75,76}$. The dyes are green or bluetinted, the perovskite films are reddish brown to yellowish (Fig. S13, Supplementary Information), and the SiMPF in this study has chromaticity coordinates in the central region of the chromaticity diagram.

\section{Performance of neutral-color transparent solar cells with flexibility}

Figure 3c displays the $I-V$ characteristics of the TSCs employing the slanted-tip SiMPFs, and the detailed photovoltaic performance is summarized in Table 5. Since HNAD etching only affects the upper part of the $\mathrm{Si}$ microwires already exposed in the first step, $\mathrm{Al}_{2} \mathrm{O}_{3}$ passivation on the sides of the microwire array still exists regardless of the flat or slanted-tip. Therefore, compared to the TSCs based on flat-tip SiMPFs, the $V_{\mathrm{oc}}$ and FF of the slanted devices remained unchanged, but $J_{\text {sc }}$ increased significantly. In addition, the fabrication process including HNAD etching is still reproducible. As shown in Fig. S14, the box plot of the photovoltaic parameters of slanted-tip SiMPFs also has a narrow distribution. Interestingly, as the pitch of the SiMPFs increased, the enhancement in $J_{\text {sc }}$ $\left(\Delta J_{\mathrm{sc}}\right)$ increased, which is in good agreement with the changes in the light absorption as a function of the pitch of the flat and slanted samples. The TSC with a pitch of $4 \mu \mathrm{m}$ exhibited the highest efficiency of $8.07 \%$. Figure $3 \mathrm{~d}$ shows the EQE spectra of slanted TSCs with different pitches from 4 to $7 \mu \mathrm{m}$ in the wavelength range of 400 $-1100 \mathrm{~nm}$. The integrated $J_{\mathrm{sc}}$ is consistent with that determined from the $J-V$ curves. Comparison of the EQEs of the flat and slanted samples shows a significant increase in the current density of the slanted samples in the nearinfrared region, rather than in the visible region (Fig. S15, Supplementary Information). In other words, the enhancement in the efficiency of the TSCs is achieved by improving the absorption in the near-infrared region (800-1100 nm) without compromising the visible transparency, which is one of key parameters for TSCs.

Figure 3e shows a plot of the efficiency vs. the average transmittance of visible light for various neutral-color transparent solar cells, including those based on perovskites, organic semiconductors, and amorphous silicon. Zhang et al. ${ }^{77}$ demonstrated an $~ 9 \%$ neutral-color TSC by taking advantage of a NIR nonfullerene acceptor at a light transmittance of $20 \%$. Chueh et al. $^{78}$ fabricated a TSC with an efficiency of $5.63 \%$ at a light transmittance of $13 \%$ by reducing the thickness of the light-absorbing layer and the silver electrode in an organic solar cell. Song Yi et al. ${ }^{79}$ demonstrated a transparent organic solar cell in which the metal electrodes were replaced with graphene electrodes, achieving an efficiency of $3.8 \%$ at a visible transparency of $51 \%$. Eperon et al. ${ }^{80}$ introduced microstructured perovskites and enabled the transmission of light through devices, achieving an efficiency of $\sim 7 \%$ at a visible transparency of $8 \%$. Alternatively, even when a thin layer of a$\mathrm{Si}(<300 \mathrm{~nm})$ is utilized for the active layer in $\mathrm{TSCs}^{81}$, the adjustable transparency range is very limited. When the transmittance is increased, an uncontrolled shunt path is formed in thin a-Si, resulting in serious efficiency loss, which further worsens the transmittance gain. Overall, the performance is comparable with that of the state-of-theart TSCs based on organics or perovskite, but the transparency is low in comparison to TSCs that have high transmittance $(T>30 \%)$. To improve transparency, surface treatment of the PDMS that filled the spaces between the microwires can be further considered in future work. 


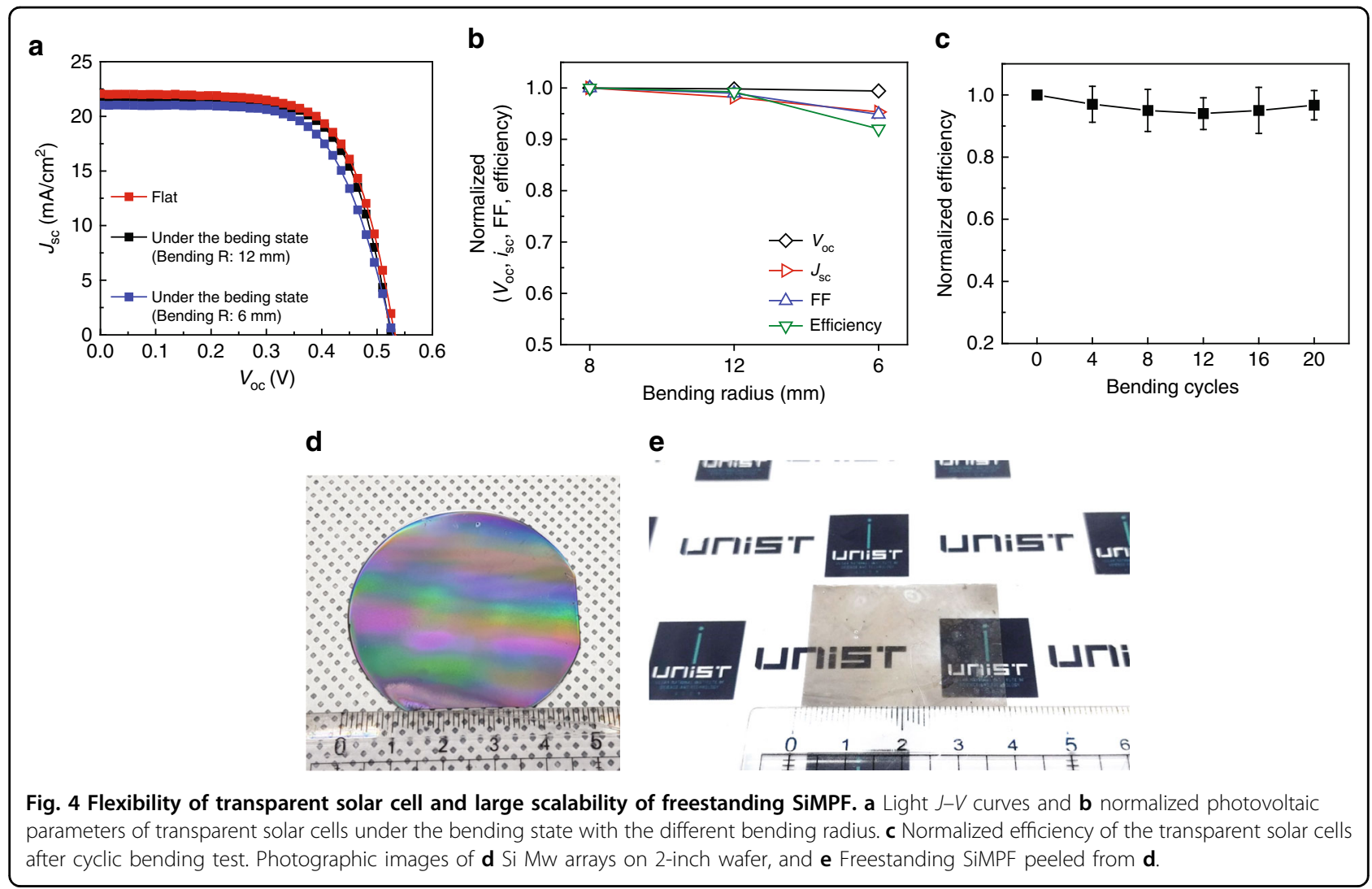

Table 6 The photovoltaic parameters of transparent solar cells under the bending state with different bending radius.

\begin{tabular}{lllll}
\hline Bending radius & $\boldsymbol{V}_{\text {oc }}(\mathrm{V})$ & $\boldsymbol{J}_{\mathbf{s c}}\left(\mathrm{mA} / \mathrm{cm}^{2}\right)$ & FF & Eff. (\%) \\
\hline$\infty$ (Flat) & 0.529 & 22.07 & 0.683 & 7.79 \\
$12 \mathrm{~mm}$ & 0.528 & 21.88 & 0.676 & 7.81 \\
$6 \mathrm{~mm}$ & 0.526 & 21.42 & 0.648 & 7.30 \\
\hline
\end{tabular}

However, the transparency of the devices based on the SiMPF platform can be easily tuned from 10 to $55 \%$ by varying the spacing between the SiMWs, unlike other developed TSCs. More importantly, the TSC based on SiMPF can be applied as a flexible solar cell due to the thin thickness of the device and intrinsic robustness of PDMS $^{82-84}$, whereas most of the currently reported TSCs utilizing organics or perovskite are fabricated by spincoating on rigid glass, resulting in inflexibility. The TSC was characterized under the bending state and after a cyclic bending test. Interestingly, the performance of the transparent solar cells composed of PEDOT:PSS/Si MW-PDMS composite/IZO did not decreased severely in the bending state for bending radii of $12 \mathrm{~mm}$ and $6 \mathrm{~mm}$ (Fig. 4a, b). The photovoltaic parameters of the device in the bending state are summarized in Table 6 . In addition, as shown in Fig. 4c, after the cyclic bending test with a bending radius of $6 \mathrm{~mm}$, the normalized efficiency was almost maintained without a significant decrease, indicating that the transparent solar cell can be bent. Furthermore, SiMPF can be easily sized to wafer-scale unlike perovskite and organics, as shown in Fig. 4d, e, because it were fabricated using large-area processes, such as photolithography and dry etching.

\section{Discussion}

Stretchability of the SiMPF platform and its application for stretchable solar cells

As shown in Fig. 5a, the optical diffraction patterns are produced by transmitted light, demonstrating the Fourier transform properties between the reciprocal domains. Under the application of $50 \%$ strain, the long-range order representing the reciprocal domains of the wire arrays was still observed, indicating that the morphology is maintained without any structural changes. After coating PEDOT:PSS on SiMPF before the deposition of IZO, we measured the changes in the resistances of PEDOT:PSS for each strain value at $5 \%$ strain intervals during stretching $(0 \rightarrow 50 \%)$ and releasing $(50 \rightarrow 0 \%$ ) (Fig. $5 \mathrm{~b}$ ). After one cycle of stretching and releasing, the resistance of PEDOT:PSS coated on SiMPF recovered to the original value. Moreover, the 

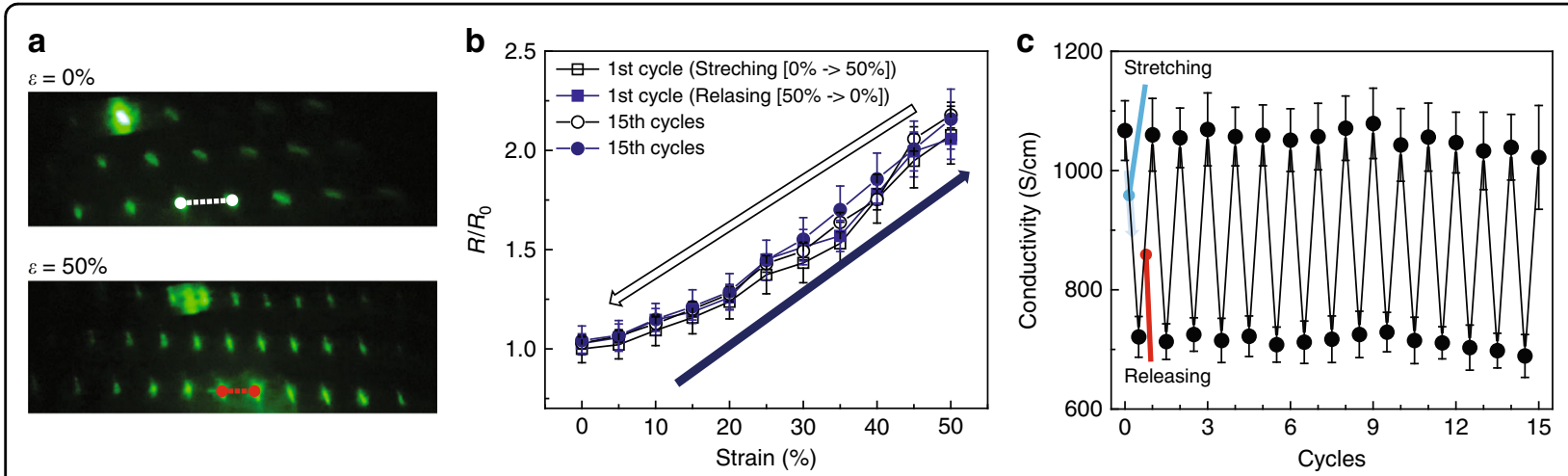

Fig. 5 Stretchability of freestanding SiMPF. a Optical diffraction pattern of the SiMPF at $\varepsilon=0$ and $50 \%$. $\mathbf{b}$ The changes in resistances at each strain values as the $5 \%$ strain interval during stretching $(0 \rightarrow 50 \%)$ and releasing state $(50 \rightarrow 0 \%)$ at 1 cycle and 15 cycles. c Changes in conductivity when the applied strain is 0 and $50 \%$ under repetition of stretching and releasing cycles.

changes in resistance after the 15th cycle are very similar to the value of the 1st cycle, indicating the durability of the samples. Moreover, under the application of a strain of $50 \%$, the conductivity of the sample is maintained at up to $\sim 700 \mathrm{~S} / \mathrm{cm}$, which is still a feasible value and applicable for photovoltaics. Additionally, this stretchable characteristic of robust SiMPF is retained during multiple cycles of strain and release (Fig. 5c). The stretchability of this platform can extend its applications to a solar window in a unique way. For example, under the application of strain, the pitch can be elongated at the same time. Therefore, as shown in Fig. S16, the transparency can be tuned as a function of strain, and it will also be applicable for a solar window that can control the transparency, allowing it to be used for both privacy and electricity generation depending on the situation.

Applying uniaxial or biaxial strain is a more severe condition for electronics than bending strain ${ }^{85,86}$. In the case of IZO, which is currently utilized as the bottom contact of transparent solar cells, it is not stretchable, but it is bendable. For stretchable solar cells, an EGain (eutectic gallium-indium)-Ag particle electrode was utilized, which exhibit no significant changes in sheet resistance under the application of strain, unlike IZO (Fig. S17). Under the application of strain, the stretchable solar cells still operate, but the performance deteriorates. The series resistance of the devices is increased due to the reduction in the conductivity of PEDOT:PSS under application of strain, resulting in a decrease in FF and $J_{\mathrm{sc}}$. However, after one cycle of stretching and release, the photovoltaic parameters are recovered due to the stretchable property of PEDOT:PSS/n-SiMPF (Fig. S18a). The integrated $J_{\text {sc }}$ from the EQE spectra of the device under application of different strains in the wavelength range from 400 to $1100 \mathrm{~nm}$ is consistent with the $J_{\mathrm{sc}}$ determined from the light $J-V$ curves (Fig. S18b). The photovoltaic parameters of stretchable solar cells taking advantage of EGain-Ag particles as the bottom contact under the application of different strains are summarized in Table S1. After repeated cycles (stretching $\rightarrow$ releasing) of 1,5 , and 10 times, the performances of the stretchable solar cells composed of PEDOT:PSS/SiMW-PDMS composite/EGain-Ag particles were maintained without significant degradation (Fig. S19a and Table S2). Moreover, when each parameter was normalized against its initial value, there was no significant difference regarding $V_{\mathrm{oc}}, J_{\mathrm{sc}}, \mathrm{FF}$ and efficiency, indicating that stretchable solar cells are mechanically durable (Fig. S19b).

In summary, freestanding SiMPFs with adjustable transparency were fabricated for application in true-color transparent solar cells with flexibility. Novel wet etching was utilized to transform the morphology of the flat-top surface of the SiMPF to a slanted shape. Finite-difference time-domain simulation was used to elucidate the phenomena underlying the enhanced absorption, indicating re-absorption of light by adjacent SiMWs and an enhanced electric field in SiMWs with a slanted morphology. Furthermore, neutral-color transparent solar cells based on slanted-tip SiMPFs demonstrated a PCE of $8.07 \%$ at $10 \%$ average transmittance. Moreover, the platform is based on the c-Si wafer, which is already verified and widely used in the Si PV market. In addition, the freestanding platform is fabricated by photolithography and etching processes that are now widely used in the semiconductor industry; thus, it could be combined for advanced optics ${ }^{87}$, including microcavities and waveguides fabricated by lithography and etching for enhancing the performance. Finally, the transparent solar cell in this study is an ideal that can be utilized in real-world applications such as building-integrated photovoltaics, automobile attachable devices, or the Internet of things in the future. 


\section{Materials and methods}

\section{Fabrication of Si microwire arrays}

Silicon microwire arrays were fabricated using $n$-Si wafers (Czochralski-grown, $525 \pm 25-\mu \mathrm{m}$ thick, $0.01-0.02 \Omega \mathrm{cm}$, Unisill Inc.). A 20-nm-thick conformal $\mathrm{SiO}_{2}$ oxide layer was grown by dry thermal oxidation for $30 \mathrm{~min}$ at $1000{ }^{\circ} \mathrm{C}$ under a pure $\mathrm{O}_{2}$ atmosphere. Thereafter, a 70-nm $\mathrm{SiO}_{2}$ thin film was deposited by plasma-enhanced chemical vapor deposition (PEH-600, Sorona). Circular dot arrays ( $2 \mu \mathrm{m}$ in diameter, 4, 5, 6, and $7 \mu \mathrm{m}$ center-to-center distance) were patterned on the $\mathrm{Si}$ substrate by image reversal photolithography with an AZ5214 (AZ Electronic Materials) instrument. After deposition of $\mathrm{Cr}(300 \mathrm{~nm})$ on the patterned $\mathrm{Si}$ photoresist, the residue was removed with acetone, resulting in $\mathrm{Cr}$ microdot arrays as a metal mask for the $\mathrm{Si}$ microwires. The $\mathrm{Si}$ was then etched by deep-reactive ion etching (DRIE) (Tegal 200). The DRIE process was carried out using $\mathrm{SF}_{6}(250 \mathrm{sccm}) / \mathrm{C}_{4} \mathrm{~F}_{8}(150 \mathrm{sccm})$ in cyclic etching mode and passivation with a $1500 \mathrm{~W}$ source power, using 40 mTorr gas pressure and $100 \mathrm{~W}$ stage power. The $\mathrm{Cr}$ metal mask was removed with a $\mathrm{Cr}$ etchant after the DRIE process.

\section{Fabrication of Si microwire array/PDMS}

A 15-nm-thick $\mathrm{Al}_{2} \mathrm{O}_{3}$ layer was deposited on the $\mathrm{Si}$ microwire arrays by atomic layer deposition (Lucida $\mathrm{D} 100, \mathrm{NCD})$ to passivate the $\mathrm{Si}$ surface. The $\mathrm{Al}_{2} \mathrm{O}_{3}$-coated $\mathrm{Si}$ microwire arrays were treated with $\mathrm{O}_{2}$ plasma by reactive ion etching (RIE, Labstar) for a uniform coating with PDMS. The microwire arrays were then coated with a solution containing $5 \mathrm{~g}$ hexamethylcyclotrisiloxane (Sigma Aldrich), 1 g PDMS (Sylgard 184, Dow Corning), $0.10 \mathrm{~g}$ PDMS curing agent, and $5 \mathrm{ml}$ dichloromethane. The solution was spin-coated onto the samples at $800 \mathrm{rpm}$ for $120 \mathrm{~s}$ and $1200 \mathrm{rpm}$ for $10 \mathrm{~s}$, and cured at $100{ }^{\circ} \mathrm{C}$ for $20 \mathrm{~min}$. PDMS etching was performed to expose the tip of the Si microwires via RIE at an RF power of $500 \mathrm{~W}$. The samples were placed into the chamber at a pressure of $60 \mathrm{mTorr}$; the total gas flow rate was $80 \mathrm{sccm}$, with $\mathrm{O}_{2}$ gas and $\mathrm{SF}_{6}$ gas flow rates of 50 and $30 \mathrm{sccm}$, respectively.

\section{Fabrication of freestanding slanted-tip SiMPF}

After dry etching of residual PDMS, only the upper part of the Al203-coated Si microwires is exposed. Apart from this, the filled PDMS remains in the $\mathrm{Al}_{2} \mathrm{O}_{3}$-coated $\mathrm{Si}$ microwires and prevents the etching of $\mathrm{Al}_{2} \mathrm{O}_{3}$ in the other part. After that, the exposed $\mathrm{Al}_{2} \mathrm{O}_{3}$ layers on the upper part of the $\mathrm{Si}$ microwires were etched with $85 \% \mathrm{H}_{3} \mathrm{PO}_{4}$ at $50{ }^{\circ} \mathrm{C}$ for $180 \mathrm{~s}$. Thereafter, the $\mathrm{Si}$ microwire arrays were chemically etched with a solution comprising $\mathrm{HF} / \mathrm{HNO}_{3} /$ $\mathrm{CH}_{3} \mathrm{COOH} / \mathrm{DMF}$ in a volume ratio of $3: 6: 0.3: 0.7$. The detailed and overall etching process to fabricate the slanted-tip $\mathrm{Si}$ microwire-PDMS composite film is described in Fig. S20. The Si microwire array-PDMS composite film was mechanically peeled off from the parent substrate. For proper contact with the bottom electrodes and top junction layer, the composites were slightly etched with a $1: 2$ mixture of $1.0 \mathrm{M}$ tetrabutylammonium fluoride in tetrahydrofuran (Sigma Aldrich) and dimethylformamide for 10 s. A 200-nm-thick indium-doped $\mathrm{ZnO}$ thin film was coated onto the composite films as a bottom electrode by RF sputtering (Infovion). A highly conductive PEDOT:PSS (CLEVIOS $\mathrm{PH}$ 1000) solution containing $9 \mathrm{wt} \%$ ethylene glycol and 0.1 wt\% Triton X-100 was spin-coated onto the composite films to form the junction.

\section{Optical simulation of Si microwire arrays}

Numerical simulation was performed with lumerical finite-difference time-domain (FDTD) as the timedependent Maxwell's equation solver. We used material data from the literature to provide the refractive index information for $\mathrm{Si}, \mathrm{PDMS}$, and $\mathrm{Al}_{2} \mathrm{O}_{3}$. As a condition for the simulation of the incident light, a plane-wave parallel to the microwire was used. As the boundary condition for the simulation, Bloch boundary conditions were used in the $x$ and $y$ directions, and the perfect matched layer boundary was used in the $z$ direction. For the absorption and reflection spectra and time-resolved reflected light of the microwire, the simulations were performed using the same parameters as those employed in the experiments.

\section{Characterization of transparent solar cells}

The morphologies of the Si microwires and composites were characterized by field-emission scanning electron microscopy (Quanta200 FE-SEM, FEI). The transmittance and reflectance of the $\mathrm{Si}$ microwire-PDMS composite films were measured by using a UV-Vis-NIR spectrophotometer (Cary 5000, Agilent) with an integrating sphere to account for the total diffuse and specular light reflected and transmitted from the samples. The color coordinates of the samples were recorded with a goniometer (Neolight G500, PIMAX) equipped with a compact array spectrometer (CAS $140 \mathrm{CT}$, Instrument system) using 1-sun illumination. The external quantum efficiency spectra were recorded in the wavelength range 400-1100 nm using a xenon light source and a monochromator. The active area of the devices equalled $0.5 \times$ $0.5 \mathrm{~cm}^{2}$. A shadow mask with an area of $0.25 \mathrm{~cm}^{2}$ was also used for precisely defining the active area. The solar cell results were therefore referenced to the active area. The photovoltaic performance of the solar cells was examined under AM 1.5 G illumination using a solar simulator. The incident flux was confirmed using a NREL-calibrated solar cell (PV Measurements, Inc.) 


\section{Acknowledgements}

This research was supported by Mid-career Researcher Program through the National Research Foundation of Korea (NRF) grant funded by the Korea government (NRF-2018R1A2B2003720).

\section{Author contributions}

S.B.K. and K.J.C. designed the experiments, analyzed the data, and wrote the paper. S.B.K. carried out the experiments and fabrication of SiMPF and devices. S.B.K., J.K., and C.K performed the optical simulations. M.H.J., C.U.K., and A.S. conducted the optical property measurements. All authors discussed the results and commented on the manuscript.

\section{Conflict of interest}

The authors declare that they have no conflict of interest.

Supplementary information is available for this paper at https://doi.org/ 10.1038/s41377-019-0234-y.

Received: 19 August 2019 Revised: 22 November 2019 Accepted: 3 December 2019

Published online: 12 December 2019

\section{References}

1. Li, D. H. W., Lam, T. N. T. \& Cheung, K. L. Energy and cost studies of semitransparent photovoltaic skylight. Energy Convers. Manag. 50, 1981-1990 (2009).

2. Wong, P. W. et al. Semi-transparent PV: thermal performance, power generation, daylight modelling and energy saving potential in a residential application. Renew. Energy 33, 1024-1036 (2008).

3. Chang, S. Y. et al. Transparent polymer photovoltaics for solar energy harvesting and beyond. Joule 2, 1039-1054 (2018).

4. Guo, C. F. et al. Metallic nanostructures for light trapping in energy-harvesting devices. Light.: Sci. Appl. 3, e161 (2014).

5. Yuan, L. G. et al. Semi-transparent perovskite solar cells: unveiling the trade-off between transparency and efficiency. J. Mater. Chem. A 6, 19696-19702 (2018).

6. Husain, A. A. F. et al. A review of transparent solar photovoltaic technologies. Renew. Sustain. Energy Rev. 94, 779-791 (2018).

7. Heo, J. H. et al. Semitransparent $\mathrm{FAPbl}_{3-x} \mathrm{Br}_{x}$ perovskite solar cells stable under simultaneous damp heat $\left(85^{\circ} \mathrm{C} / 85 \%\right)$ and 1 sun light soaking. Adv. Mater. Technol. 4, 1800390 (2019).

8. Heo, J. H. et al. Stable semi-transparent $\mathrm{CH}_{3} \mathrm{NH}_{3} \mathrm{Pbl}_{3}$ planar sandwich solar cells. Energy Environ. Sci. 8, 2922-2927 (2015).

9. Roldán-Carmona, C. et al. High efficiency single-junction semitransparent perovskite solar cells. Energy Environ. Sci. 7, 2968-2973 (2014).

10. Xue, Q. F. et al. Recent advances in semi-transparent polymer and perovskite solar cells for power generating window applications. Energy Environ. Sci. 11, 1688-1709 (2018).

11. Han, K. et al. Fully solution processed semi-transparent perovskite solar cells with spray-coated silver nanowires/ZnO composite top electrode. Sol. Energy Mater. Sol. Cells 185, 399-405 (2018).

12. Kim, G. M. \& Tatsuma, T. Semi-transparent perovskite solar cells developed by considering human luminosity function. Sci. Rep. 7, 10699 (2017).

13. Kim, K. M. et al. Work function optimization of vacuum free top-electrode by PEDOT: PSS/PEI interaction for efficient semi-transparent perovskite solar cells. Sol. Energy Mater. Sol. Cells 176, 435-440 (2018).

14. Tirado, J. et al. Low-cost semi-transparent copper sulfide electrode for indiumtin-oxide-free perovskite solar cells. Thin Solid Films 662, 90-96 (2018).

15. Biancardo, M., West, K. \& Krebs, F. C. Optimizations of large area quasi-solidstate dye-sensitized solar cells. Sol. Energy Mater. Sol. Cells 90, 2575-2588 (2006).

16. Zhang, K. et al. High-performance, transparent, dye-sensitized solar cells for see-through photovoltaic windows. Adv. Energy Mater. 4, 1301966 (2014).

17. Tai, Q. D. et al. In situ prepared transparent polyaniline electrode and its application in bifacial dye-sensitized solar cells. ACS Nano 5, 3795-3799 (2011).

18. Tagliaferro, R. et al. Interplay between transparency and efficiency in dye sensitized solar cells. Opt. Express 21, 3235-3242 (2013).

19. Zhang, X. L., Hägglund, C. \& Johansson, E. M. J. Highly efficient, transparent and stable semitransparent colloidal quantum dot solar cells: a combined numerical modeling and experimental approach. Energy Environ. Sci. 10, 216-224 (2017)

20. Fang, $\mathrm{H}$. $\mathrm{H}$. et al. Photoexcitation dynamics in solution-processed formamidinium lead iodide perovskite thin films for solar cell applications. Light: Sci. Appl. 5, e16056 (2016)

21. Zhao, Y. C. et al. Quantification of light-enhanced ionic transport in lead iodide perovskite thin films and its solar cell applications. Light.: Sci. Appl. 6, e16243 (2017).

22. Kojima, A. et al. Organometal halide perovskites as visible-light sensitizers for photovoltaic cells. J. Am. Chem. Soc. 131, 6050-6051 (2009).

23. Lee, M. M. et al. Efficient hybrid solar cells based on meso-superstructured organometal halide perovskites. Science 338, 643-647 (2012).

24. Gu, L. L. \& Fan, Z. Y. Perovskite/organic-semiconductor heterojunctions for ultrasensitive photodetection. Light.: Sci. Appl. 6, e17090 (2017).

25. Xie, $\mathrm{C}$. et al. Ultrasensitive broadband phototransistors based on perovskite/ organic-semiconductor vertical heterojunctions. Light.: Sci. Appl. 6, e17023 (2017).

26. Jeon, N. J. et al. Solvent engineering for high-performance inorganic-organic hybrid perovskite solar cells. Nat. Mater. 13, 897-903 (2014).

27. Jeon, N. J. et al. Compositional engineering of perovskite materials for highperformance solar cells. Nature 517, 476-480 (2015).

28. Eperon, G. E. et al. The importance of moisture in hybrid lead halide perovskite thin film fabrication. ACS Nano 9, 9380-9393 (2015).

29. Della Gaspera, E. et al. Ultra-thin high efficiency semitransparent perovskite solar cells. Nano Energy 13, 249-257 (2015).

30. Zhang, $M$. et al. Electrode design to overcome substrate transparency limitations for highly efficient $1 \mathrm{~cm}^{2}$ mesoscopic perovskite solar cells. Joule $\mathbf{2}$ 2694-2705 (2018)

31. Jung, J. W., Chueh, C. C. \& Jen, A. K. Y. High-performance semitransparent perovskite solar cells with $10 \%$ power conversion efficiency and $25 \%$ average visible transmittance based on transparent CuSCN as the hole-transporting material. Adv. Energy Mater. 5, 1500486 (2015).

32. Cui, Y. et al. Efficient semitransparent organic solar cells with tunable color enabled by an ultralow-bandgap nonfullerene acceptor. Adv. Mater. 29, 1703080 (2017)

33. Liu, F. et al. Efficient semitransparent solar cells with high nir responsiveness enabled by a small-bandgap electron acceptor. Adv. Mater. 29, 1606574 (2017).

34. Browning, J. et al. Adhesive strength of rubber bonded to $\mathrm{Al}_{2} \mathrm{O}_{3}$ surfaces: the role of chemistry and morphology. J. Adhes. 75, 229-253 (2001).

35. Tan, S. H. et al. Oxygen plasma treatment for reducing hydrophobicity of a sealed polydimethylsiloxane microchannel. Biomicrofluidics 4, 032204 (2010).

36. Tang, K. C. et al. Evaluation of bonding between oxygen plasma treated polydimethyl siloxane and passivated silicon. J. Phys.: Conf. Ser. 34, 155-161 (2006).

37. Lee, K. et al. 17.6\%-Efficient radial junction solar cells using silicon nano/micro hybrid structures. Nanoscale 8, 14473-14479 (2016).

38. Oh, J., Yuan, H. C. \& Branz, H. M. An 18.2\%-efficient black-silicon solar cel achieved through control of carrier recombination in nanostructures. Nat. Nanotechnol. 7, 743-748 (2012).

39. Pawlik, M. et al. Electrical and chemical studies on $\mathrm{Al}_{2} \mathrm{O}_{3}$ passivation activation process. Energy Procedia 60, 85-89 (2014).

40. Repo, P. et al. Silicon surface passivation by $\mathrm{Al}_{2} \mathrm{O}_{3}$ : effect of $A L D$ reactants Energy Procedia 8, 681-687 (2011).

41. Simon, D. K. et al. Symmetrical $\mathrm{Al}_{2} \mathrm{O}_{3}$-based passivation layers for $p$ - and $n$-type silicon. Sol. Energy Mater. Sol. Cells 131, 72-76 (2014).

42. Schmidt, J. et al. Advances in the surface passivation of silicon solar cells. Energy Procedia. 15, 30-39 (2012).

43. Kang, S. B. et al. Self-assembled, highly crystalline porous ferroelectric poly (vinylidene fluoride-co-trifluoroethylene) interlayer for Si/organic hybrid sola cells. Nano Energy 41, 243-250 (2017).

44. Kang, S. B. et al. Transfer of ultrathin molybdenum disulfide and transparent nanomesh electrode onto silicon for efficient heterojunction solar cells. Nano Energy 50, 649-658 (2018).

45. Chao, Y. C. et al. Light scattering by nanostructured anti-reflection coatings. Energy Environ. Sci. 4, 3436-3441 (2011).

46. Garnett, E. \& Yang, P. D. Light trapping in silicon nanowire solar cells. Nano Lett. 10, 1082-1087 (2010)

47. Kibria, M. G. et al. Visible light-driven efficient overall water splitting using ptype metal-nitride nanowire arrays. Nat. Commun. 6, 6797 (2015). 
48. Polman, A. \& Atwater, H. A. Photonic design principles for ultrahigh-efficiency photovoltaics. Nat. Mater. 11, 174-177 (2012).

49. Nuzaihan, M. N. M. et al. Top-down nanofabrication and characterization of 20 $\mathrm{nm}$ silicon nanowires for biosensing applications. PLOS ONE 11, e0152318 (2016).

50. Seo, K. et al. Multicolored vertical silicon nanowires. Nano Lett. 11, 1851-1856 (2011).

51. Sun, Y. G. et al. Top-down fabrication of semiconductor nanowires with alternating structures along their longitudinal and transverse axes. Small 1, 1052-1057 (2005).

52. Fasoli, A. \& Milne, W. I. Overview and status of bottom-up silicon nanowire electronics. Mater. Sci. Semiconductor Process. 15, 601-614 (2012).

53. Hannon, J. B. et al. The influence of the surface migration of gold on the growth of silicon nanowires. Nature 440, 69-71 (2006).

54. Ma, D. D. D. et al. Small-diameter silicon nanowire surfaces. Science 299 1874-1877 (2003).

55. Gunawan, O. \& Guha, S. Characteristics of vapor-liquid-solid grown silicon nanowire solar cells. Sol. Energy Mater. Sol. Cells 93, 1388-1393 (2009).

56. Toor, F. et al. Multi-scale surface texture to improve blue response of nanoporous black silicon solar cells. Appl. Phys. Lett. 99, 103501 (2011).

57. Yu, L. W. et al. Bismuth-catalyzed and doped silicon nanowires for onepump-down fabrication of radial junction solar cells. Nano Lett. 12, 4153-4158 (2012).

58. Robbins, H. \& Schwartz, B. Chemical etching of silicon I. the system $\mathrm{HF}_{1} \mathrm{HNO}_{3}$ and $\mathrm{H}_{2}$ O. J. Electrochem. Soc. 106, 505-508 (1959).

59. Hamzah, A. A. et al. Optimization of HNA etching parameters to produce high aspect ratio solid silicon microneedles. J. Micromech. Microeng. 22, 095017 (2012).

60. Hamzah, A. A., Majlis, B. Y. \& Ahmad, I. HF etching of sacrificial spin-on glass in straight and junctioned microchannels for MEMS microstructure release. J. Electrochem. Soc. 154, D376-D382 (2007).

61. Lippold, $\mathrm{M}$. et al. Etching silicon with $\mathrm{HF}-\mathrm{HNO}_{3}-\mathrm{H}_{2} \mathrm{SO}_{4} / \mathrm{H}_{2} \mathrm{O}$ mixturesunprecedented formation of trifluorosilane, hexafluorodisiloxane, and Si-F surface groups. Eur. J. Inorg. Chem. 2012, 5714-5721 (2012).

62. Roman, P. et al. Current advances in anhydrous hf/organic solvent processing of semiconductor surfaces. Solid State Phenom. 145-146, 231-234 (2009).

63. Tarakanova, E. G. \& Yukhnevich, G. V. Composition and structure of heteroassociates formed in the HF-N, N dimethylformamide binary liquid system. Russian Chem. Bull. 60, 81-88 (2011).

64. El Gawhary, O., Severini, S. \& Christillin, P. Which group velocity of light in a dispersive medium? Eur. Phys. J. 126, 1-5 (2011).

65. Kosten, E. D., Warren, E. L. \& Atwater, H. A. Ray optical light trapping in silicon microwires: exceeding the $2 n^{2}$ intensity limit. Opt. Express 19, 3316-3331 (2011).

66. Putnam, M. C. et al. Si microwire-array solar cells. Energy Environ. Sci. 3, 1037-1041 (2010)

67. Sai, $\mathrm{H}$. et al. Light trapping effect of submicron surface textures in crystalline $\mathrm{Si}$ solar cells. Prog. Photovolt. 15, 415-423 (2007).
68. Zhao, J. H., Wang, A. H. \& Green, M. A. 24.5\% efficiency silicon PERT cells on MCZ substrates and $24.7 \%$ efficiency PERL cells on FZ substrates. Prog. Photovolt. 7, 471-474 (1999).

69. Hu, L. \& Chen, G. Analysis of optical absorption in silicon nanowire arrays for photovoltaic applications. Nano Lett. 7, 3249-3252 (2007).

70. Preston, C. et al. Silver nanowire transparent conducting paper-based electrode with high optical haze. J. Mater. Chem. C. 2, 1248-1254 (2014).

71. Galeotti, F. et al. Tailorable perylene-loaded fluorescent nanostructures: a multifaceted approach enabling their application in white hybrid LEDs. J. Mater. Chem. C. 4, 5407-5415 (2016).

72. Araki, T. et al. Low haze transparent electrodes and highly conducting air dried films with ultra-long silver nanowires synthesized by one-step polyol method. Nano Res. 7, 236-245 (2014).

73. Niu, Z. Q. et al. Synthesis of silver nanowires with reduced diameters using benzoin-derived radicals to make transparent conductors with high transparency and low haze. Nano Lett. 18, 5329-5334 (2018).

74. Xu, Q. S. et al. Flexible transparent conductive films on PET substrates with an AZO/AgNW/AZO sandwich structure. J. Mater. Chem. C. 2, 3750-3755 (2014).

75. Gao, S. et al. Multifunctional $\mathrm{Zn}(\mathrm{II}) / \mathrm{Cd}(\mathrm{II})$ metal complexes for tunable luminescence properties and highly efficient dye-sensitized solar cells. RSC Adv. $\mathbf{5}$ 43705-43716 (2015).

76. Gao, S. et al. An insight into the controllable synthesis of Cd(ii) complexes with a new multifunctional ligand and its application in dye-sensitized solar cells and luminescence properties. J. Mater. Chem. A 3, 6053-6063 (2015).

77. Zhang, J. W. et al. Highly efficient semitransparent organic solar cells with color rendering index approaching 100. Adv. Mater. 31, 1807159 (2019).

78. Chueh, C. C. et al. Toward high-performance semi-transparent polymer solar cells: optimization of ultra-thin light absorbing layer and transparent cathode architecture. Adv. Energy Mater. 3, 417-423 (2013).

79. Song, Y. et al. Visibly-transparent organic solar cells on flexible substrates with all-graphene electrodes. Adv. Energy Mater. 6, 1600847 (2016).

80. Eperon, G. E. et al. Neutral color semitransparent microstructured perovskite solar cells. ACS Nano 8, 591-598 (2014).

81. Wook Lim, J. et al. Highly transparent amorphous silicon solar cells fabricated using thin absorber and high-bandgap-energy n/i-interface layers. Sol. Energy Mater. Sol. Cells 128, 301-306 (2014).

82. Kang, S. B. et al. Enhanced piezoresponse of highly aligned electrospun poly (vinylidene fluoride) nanofibers. Nanotechnology 28, 395402 (2017).

83. Yang, B. et al. Nature degradable, flexible, and transparent conductive substrates from green and earth-abundant materials. Sci. Rep. 7, 4936 (2017).

84. Yang, R. S. et al. Power generation with laterally packaged piezoelectric fine wires. Nat. Nanotechnol. 4, 34-39 (2009).

85. van den Brand, J. et al. Flexible and stretchable electronics for wearable health devices. Solid-State Electron 113, 116-120 (2015)

86. Wu, W. Stretchable electronics: functional materials, fabrication strategies and applications. Sci. Technol. Adv. Mater. 20, 187-224 (2019).

87. Liu, S. et al. End-fire injection of light into high-Q silicon microdisks. Optica $\mathbf{5}$, 612-616 (2018) 